\title{
STABILITY ASSESSMENT FOR THE UNDERSEA GAS PIPELINE
}

Wen-Chien Tseng

Department of Harbor and River Engineering, National Taiwan Ocean University, Keelung, Taiwan, R.O.C, d96520003@mail.ntou.edu.tw

Lien-Kwei Chien

Department of Harbor and River Engineering, National Taiwan Ocean University, Keelung, Taiwan, R.O.C

Sheng-Tse Chuang

Department of Harbor and River Engineering, National Taiwan Ocean University, Keelung, Taiwan, R.O.C

Pei-Chi Tsai

Department of Harbor and River Engineering, National Taiwan Ocean University, Keelung, Taiwan, R.O.C

Ya-Ting Hsu

Department of Harbor and River Engineering, National Taiwan Ocean University, Keelung, Taiwan, R.O.C

See next page for additional authors

Follow this and additional works at: https://jmstt.ntou.edu.tw/journal

Part of the Civil and Environmental Engineering Commons

\section{Recommended Citation}

Tseng, Wen-Chien; Chien, Lien-Kwei; Chuang, Sheng-Tse; Tsai, Pei-Chi; Hsu, Ya-Ting; Lu, Ting-Ting; and Lin, Chu-Kuan (2010) "STABILITY ASSESSMENT FOR THE UNDERSEA GAS PIPELINE," Journal of Marine Science and Technology.

Vol. 18: Iss. 6, Article 4.

DOI: $10.51400 / 2709-6998.1938$

Available at: https://jmstt.ntou.edu.tw/journal/vol18/iss6/4

This Research Article is brought to you for free and open access by Journal of Marine Science and Technology. It has been accepted for inclusion in Journal of Marine Science and Technology by an authorized editor of Journal of Marine Science and Technology. 


\section{STABILITY ASSESSMENT FOR THE UNDERSEA GAS PIPELINE}

\section{Acknowledgements}

This research was supported by Real World Engineering Consultants INC., Taiwan and referred references by CECI Engineering Consultant Inc., Taiwan, and project by NSC 97- 2221-E-019-030. Grateful appreciation is expressed to their support.

\section{Authors}

Wen-Chien Tseng, Lien-Kwei Chien, Sheng-Tse Chuang, Pei-Chi Tsai, Ya-Ting Hsu, Ting-Ting Lu, and ChuKuan Lin 


\title{
STABILITY ASSESSMENT FOR THE UNDERSEA GAS PIPELINE
}

\author{
Wen-Chien Tseng*, Lien-Kwei Chien*, Sheng-Tse Chuang*, Pei-Chi Tsai*, \\ Ya-Ting Hsu*, Ting-Ting Lu*, and Chu-Kuan Lin**
}

Key words: undersea gas pipeline, erosion potential, dredged feasibility, pipeline stability, liquefaction.

\begin{abstract}
In general, the activities of harbour district, coastal construction and re-transportation of tide and current are all possible to influence the stability of research area and sediment environment in nearshore area. It indicates that status of deposit property of seabed and variability of sediment environment are important factors to stability and safety for the path of undersea gas pipeline. An assessment procedure and approach for the prediction of the wave-induced and earthquake-induced liquefaction potential and erosion potential are proposed for marine engineering practice.

The soil sample of this study is obtained from deposit zone of gas pipeline of seabed in Taiwan Strait. A series of Atterberg limit test, direct shear test and cyclic triaxial test were performed to investigate the soil properties of research area and also provided important information for the evaluation. On the other hand, the physical characteristic and particle size of sediment and deposit area for gas pipeline of seabed are also investigated. Finally, the analysis and evaluation for erosion potential, dredging feasibility and pipeline stability were discussed. From the results, useful information is provided to the basis of detailed design and to the evaluation for the feasibility of laying gas pipeline of seabed.
\end{abstract}

\section{INTRODUCTION}

In recent years, due to marine engineering grew up gradually in Taiwan, every kinds of marine engineering are under construction continually, including undersea signal communication cable, fiber cable, electric cable, undersea pipeline, reclaimed land, and wind energy etc. To transport oil gas, CPC Corporation laid the undersea gas pipeline which diameter is 36 inches and the length is 238 kilometers from Yung-An to

Paper submitted 05/08/09; revised 01/27/10; accepted 02/11/10. Author for correspondence: Wen-Chien Tseng (e-mail: d96520003@mail.ntou.edu.tw). *Department of Harbor and River Engineering, National Taiwan Ocean University, Keelung, Taiwan, R.O.C.

**CECI Engineering Consultant, Inc., Taipei, Taiwan, R.O.C.
Tong-Siao, and planned to lay the undersea gas pipeline in 2007 which diameter is 36 inches and the length is 135 kilometers from Taichung Harbor though Tong-Siao to Taoyuan.

Most of the rivers in Taiwan's west coast, such as Ta-chia River, Ta-an River, Hou-long River and Tou-chien River, exports a large amount of suspended sediments to Taiwan Strait every year. These suspended particles of coastal river are influenced around the ocean transport and sediment by ocean current and wave action, and this phenomenon also causes significant influence to deposit area of undersea gas pipeline from Taichung to Taoyuan coastal area. However, whether is natural coast or artificial coast such as reclaimed land, coast area belongs to sandy coast to be possible induced liquefaction. The liquefaction takes place in the sea bed which may cause the submarine pipeline of sea floor to sink, so that the submarine pipeline may be destroyed due to out of shape. Consequently, it could indicate that status of deposit property of seabed and variability of sediment environment are important factors to the stability and safety for the path of undersea gas pipeline.

A series of 2-D hydraulic model tests proposed by Chang et al. [5] were carried out to investigate the duration behavior of seabed stresses induced by progressive waves. Due to the anisotropic property of natural deposit seabed soil, the progressive waves induced vertical stress and horizontal stress have different transmit speeds and phase shift between them. The DMT-based methods developed by Kung et al. [11] also have the potential to be an alternative to the existing procedure of liquefaction evaluation, such as the SPT and CPT evaluation methods, to practically obtain a more accurate liquefaction resistance of soils. Liquefaction occurred frequently in shallow water zone, near shore area, continental slope, even in deeper seabed. Therefore, the major purpose in this study is to evaluate the seabed stability by wave, including the assessment of erosion potential, dredged feasibility and pipeline stability respectively, and is to avoid occurring instable disaster continually.

\section{STUDY METHOD}

This study includes two parts. The first part is carried out the general physical tests for the soil sample by collection in 


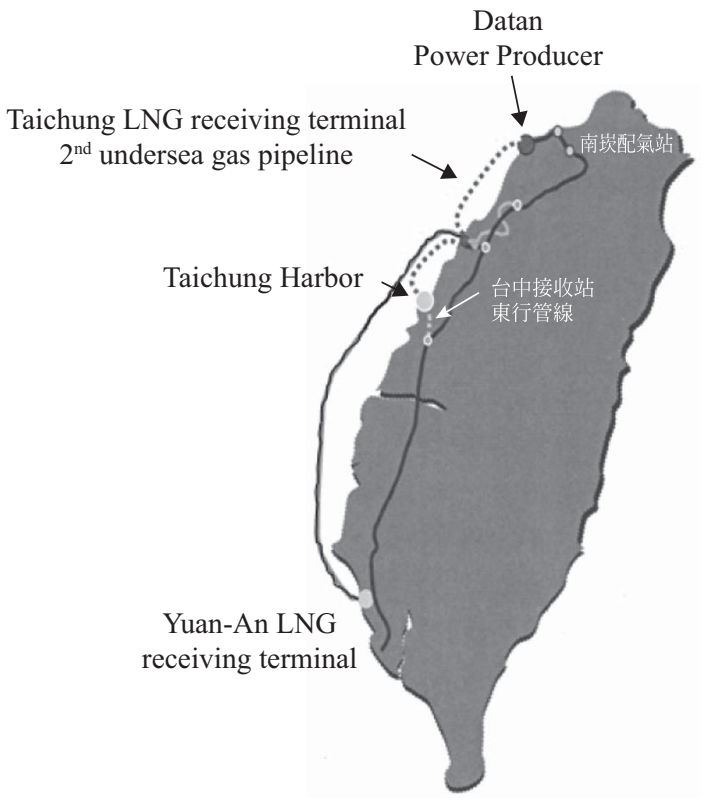

Fig. 1. The path of undersea gas pipeline.

Taiwan Strait. A series of Atterberg limit test, direct shear test and cyclic triaxial test were performed to investigate the soil properties of research area. The second part is to simulate the slope stability by earthquake force and wave induced loading from the coastal geotechnical engineering viewpoint. According to the soil properties in study area, the analysis and evaluation for erosion potential, dredged feasibility and pipeline stability were discussed. Useful information is provided to the basis of detailed design and to the evaluation for the feasibility of laying gas pipeline of seabed.

\section{TEST PLAN}

\section{Soil Material}

The path of undersea pipeline begins south from liquefied natural gas (LNG) receiving terminal in Taichung Harbor, along the coastal area of Taiwan western to north. The landing point is in Data coast of Taoyuan, and the length of pipeline is about 130 kilometers. The soil material is obtained from the second undersea gas pipeline area from Taichung Harbor to Taoyuan; the path is illustrated in Fig. 1. This study is carried out thin-tube sampler according to the pre-buried path of undersea pipeline, including 32 drilling positions. The sample depth is below from seabed surface about $3.8 \mathrm{~m}$. The sampling positions along the path of undersea pipeline are illustrated in Fig. 2.

\section{Test Plan}

The main testing in this study includes the following items.

(1) Atterberg limit test includes the liquid limit, the plastic limit and the plastic index. The testing procedure of the liquid limit is based on ASTM D4318, and the testing procedure of

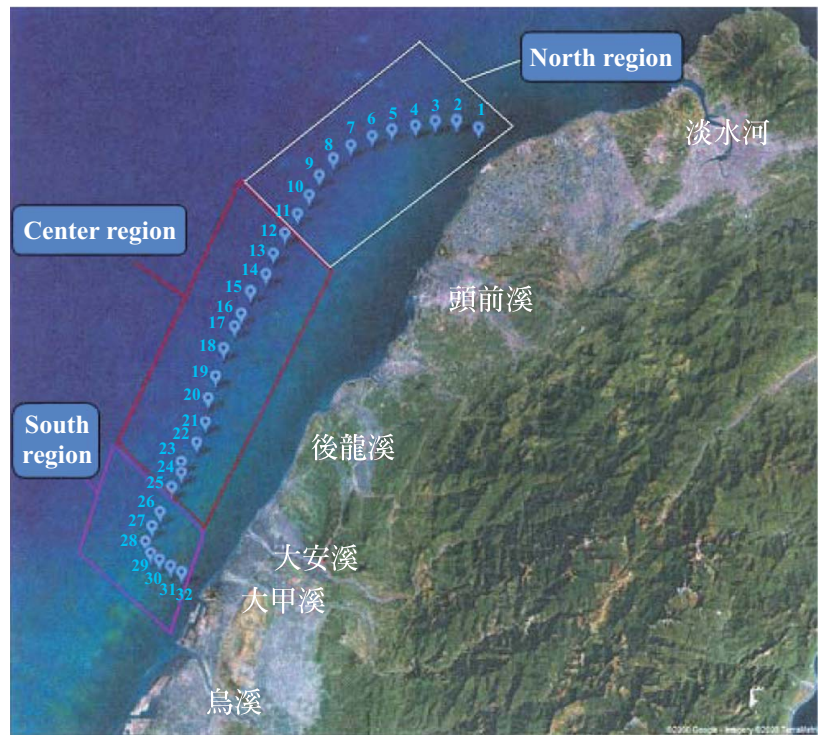

Fig. 2. The sampling holes along the path of undersea pipeline.

Table 1. Testing item for this study.

\begin{tabular}{|c|c|}
\hline Testing item & Sets \\
\hline Atterberg limit test & 30 \\
\hline *Direct shear test & 30 \\
\hline *Triaxial cyclic test & 10 \\
\hline Soil classification & 30 \\
\hline \multicolumn{2}{|c|}{ *Using remolded specimen } \\
\hline
\end{tabular}

plastic limit and plastic index is based on ASTM 4318. (2) Direct shear test, the major purpose is to determine the shear strength such as the cohesion and friction angle of soil, the testing procedure is based on ASTM D3080-72. (3) Triaxial cyclic test, it can simulate the internal variation of pore water pressure by earthquake and wave for soil, and further plot the liquefation resistance curve by the basis of testing results. (4) Soil classification, the data from partical-size analysis and Atterberg limit test are classfied by unified soil classification system (USCS) to offer relevant reference for follow-up analysis and evaluation. Remolded specimens for every testing are abided by ASTM criterion. Testing item for this study is shown in Table 1.

\section{TEST RESULT FOR SEABED SOIL}

\section{Atterberg Limit Test (ASTM D 4318-84)}

Results show that 26 groups belong to Non-Plastic. Besides previous results demonstrated that 16 groups belong to poorlysand (SP), 8 groups belong to poorly-sand/silts-sand (SP-SM), 3 groups belong to low-plasticity silt (ML), and one group for low-plasticity clay (CL), silts-sand (SM) and low-plasticity clay/low-plasticity silt (CL-ML) respectively by unified soil classification system. 


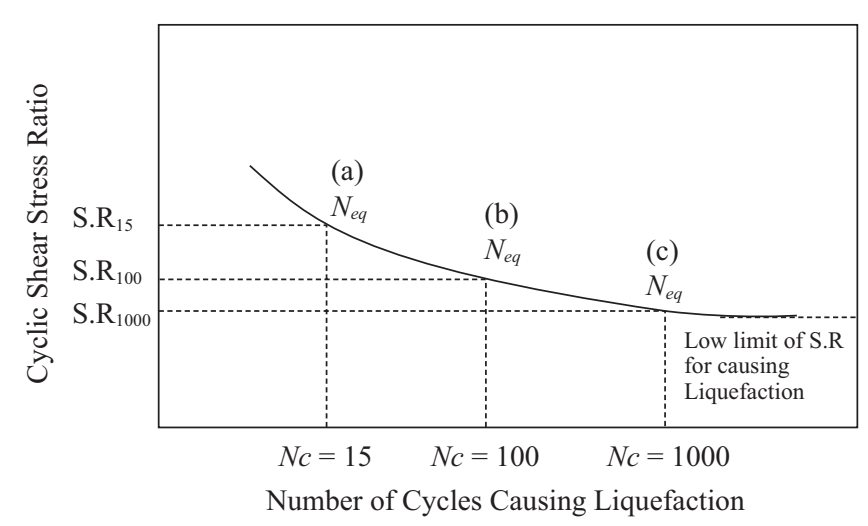

Fig. 3. Liquefaction resistance strength of seabed soil.

\section{Direct Shear Test (ASTM D 3080-72)}

The main purpose is to obtain the strength parameter for the seabed soil, including cohesion " $c$ " and friction angle " $\phi$ " in this test. The analysis of 30 sets shows that cohesion, $c$, ranges about from $28.5 \mathrm{kPa}$ to $80.4 \mathrm{kPa}$, and friction angle, $\phi$, ranges about from $15.2^{\circ}$ to $37.3^{\circ}$. The results can be referred to seabed bearing capacity, slope stability and feasibility of pipeline excavation.

\section{Cyclic Triaxial Test (ASTM D 3999-91, D 5311-92)}

In the Chien's cyclic-triaxial testing system [4], the computer programmed electronic signal for rate and magnitude of loading is applied to the electro pneumatic transducer, which then controls pneumatic amplifiers for the application of loading. The control system was compiled by Visual Basic, and the process of testing was displayed on the monitor at any stage. Cyclic triaxial tests on saturated sand are used in this study to simulate the seafloor soil under wave action. We used the moist tamping method that the soil sample divided into 5 layers to prepare specimens to simulate the seabed soil condition under the same relative density. After the specimen consolidated, a series of liquefaction test evaluated the properties of wave-induced liquefaction behaviors.

Soil liquefaction resistance strength can be expressed as cyclic shear stress, CSR, is defined as

$$
\mathrm{CSR}=\frac{\sigma_{d}}{2 \cdot \sigma_{3}^{\prime}}
$$

where $\sigma_{d}$ is the deviator stress $(\mathrm{kPa})$ under cyclic loading, $\sigma_{3}^{\prime}$ is the effective confining pressure $(\mathrm{kPa})$ for specimen bearing capacity.

Specimens are made by the moist tamping method and a series of undrained triaxial compression test were performed. The confining pressure is $30 \mathrm{kPa}$ and the frequency of earthquake is $1 \mathrm{sec}$. 10 sets of tests were performed. Based upon $\mathrm{CSR}$, it can be plotted versus the number of cycle $(\mathrm{Nc})$ causing liquefaction as shown in Fig. 3 [6]. Seed and Idriss [14] developed the evaluation method suggested $N c=15$ as number of equivalent cycle, $N_{e q}$. For a given, $N_{e q}$, the corresponding value, CSR, can be obtained from Fig. 3.

Because Seed [15] proposed the pore water pressure excitation mode, which is assumed to be based on the earthquake caused the pore water pressure dissipation behavior, usually the period for a few seconds, it can not fully simulate the process of pore water pressure generation under wave loading for a long time. Therefore, Chien et al. [6] re-modified the mode and proposed a reasonable mode to predict waves induced the behavior of pore water pressure generation for seabed soil under wave loading. If the wave is considered as the main acting force to the seabed, " $N$ eq" should be equal to $N c=1000$, for a given $N c=1000$. The corresponding value can be identified in Fig. 3, i.e., $\mathrm{CSR}_{1000}$.

Based on above test results, the cyclic shear stress ratio, $\mathrm{CSR}_{15}$, is about 0.2 to 0.33 under the depth below $1 \mathrm{~m}$ at seabed surface. Since the soil sample contains shell debris, the $\mathrm{CSR}_{15}$ of No. 1 hole is greater than 0.45 . Under the depth below $2 \mathrm{~m}$ from the seabed surface, the $\mathrm{CSR}_{15}$ is about 0.17 to 0.44. The minimum $\mathrm{CSR}_{15}$ is 0.17 which occurs in hole of No. 19 at the middle section of undersea gas pipeline. The CSR value can offer information for liquefaction potential analysis of seabed soil.

\section{Soil Classification (ASTM D 2487-85)}

Based on USCS, this study is performed with general physical tests including measurement water content, Atterberg limit test, specific gravity test and particle-size analysis test respectively, and further to obtain the particle-size distribution curve. These results can be used to classify soil property. In this study, these seabed soils belongs to SP with SM, CL and ML mostly by test results. With the engineering property viewpoint, it belongs to sandy layer with better permeability mostly.

\section{ASSESSMENT AND STABILITY ANALYSIS FOR THE UNDERSEA GAS PIPELINE}

\section{Assessment of Dredged Feasibility}

\section{1) Analysis Method}

For the dredged task, it should be obtained the relevant strength parameters about seabed soil in-situ, and choose the dredged machines to be fit for in-situ advantageously. This study is carried out direct shear tests with remolded specimens in laboratory; this test can obtain the shear strength, $\tau$, and internal friction angle, $\phi$.

A SPT-N value in-situ can be calculated from empirical equations as follows. We use Table $2[12,17]$ to assess what dredging machines could be adopted in-situ.

$$
\begin{gathered}
c=0.6 N\left(\mathrm{t} / \mathrm{m}^{2}\right) \\
\phi=27+0.3 N
\end{gathered}
$$

where $c$ is cohesion of soil, $\phi$ is friction angle of soil, and $N$ 
Table 2. $\mathrm{N}-\phi$ relationship.

\begin{tabular}{|c|c|c|}
\hline \multirow{2}{*}{ SPT-N value } & \multicolumn{2}{|c|}{ internal friction angle, $\phi$} \\
\cline { 2 - 3 } & Peck & Meyerhof \\
\hline$<4$ & $<28.5^{\circ}$ & $<30.0^{\circ}$ \\
\hline $4 \sim 10$ & $28.5^{\circ} \sim 30.0^{\circ}$ & $30.0^{\circ} \sim 35.0^{\circ}$ \\
\hline $10 \sim 30$ & $30.0^{\circ} \sim 36.0^{\circ}$ & $35.0^{\circ} \sim 40.0^{\circ}$ \\
\hline $30 \sim 50$ & $36.0^{\circ} \sim 41.0^{\circ}$ & $40.0^{\circ} \sim 45.0^{\circ}$ \\
\hline$>50$ & $>41.0^{\circ}$ & $>45.0^{\circ}$ \\
\hline
\end{tabular}

Table 3. Suggestion for dredger type.

\begin{tabular}{|c|c|c|}
\hline $\begin{array}{c}\text { Water } \\
\text { depth }\end{array}$ & Dredger type & Fit for soil \\
\hline$>10 \mathrm{~m}$ & Trailing Suction Hopper Dredger & Soft sandy soil/silt \\
\hline$<10 \mathrm{~m}$ & $\begin{array}{c}\text { Cutter Suction Dredger/ } \\
\text { Backhoe Dredger }\end{array}$ & Any soil property \\
\hline
\end{tabular}

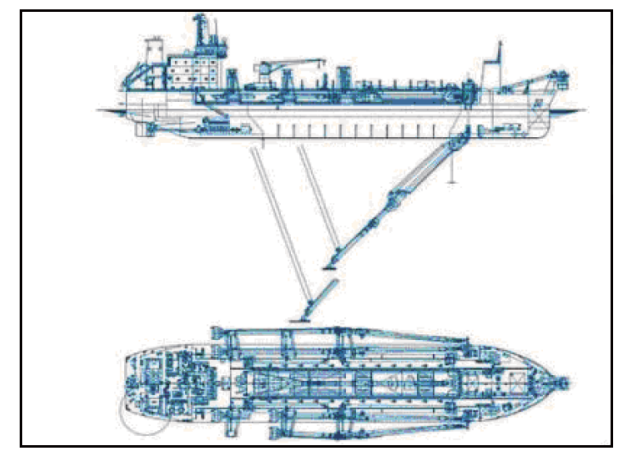

Dredge Head

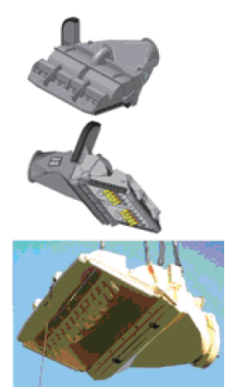

Universal

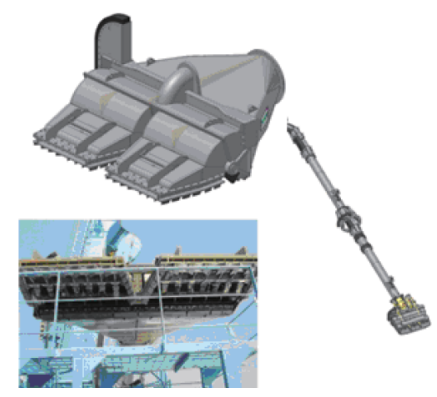

California
Fig. 4. Schematic showing the dredger for THSD.

value is obtained from standard penetration test.

The design unit adapted dredgers during construction according to water depth; it can be separate higher or below $10 \mathrm{~m}$ as Table 3:

a. When the water depth is large than $10 \mathrm{~m}$, the Trailer Suction Hopper Dredger (TSHD) is selected as shown in Fig. 4. The dredged depth of each layer is about $10-50 \mathrm{~cm}$ and depends on equipment and efficiency. The large-sized machines can reach dredging depth greater than $110 \mathrm{~m}$ for each layer depth.
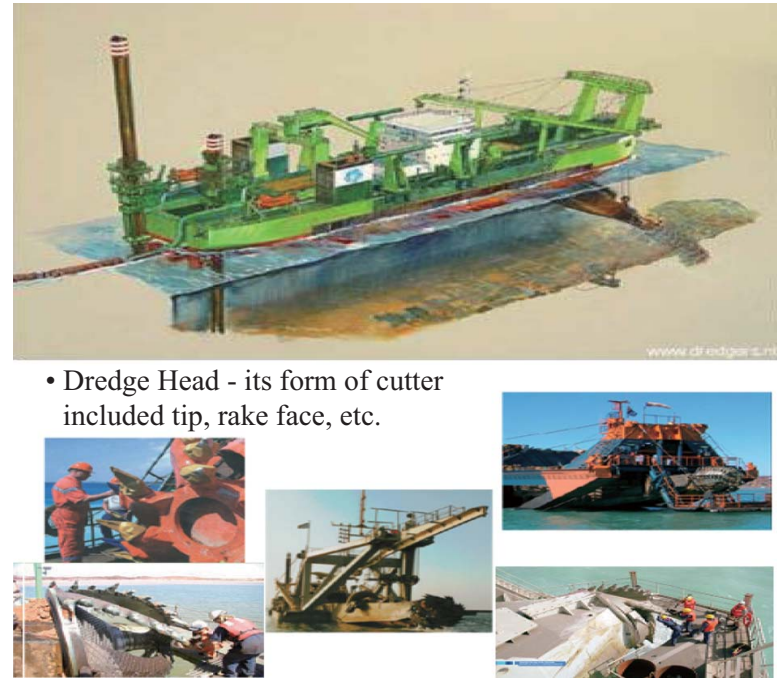

Fig. 5. Schematic showing the dredger for CSD.

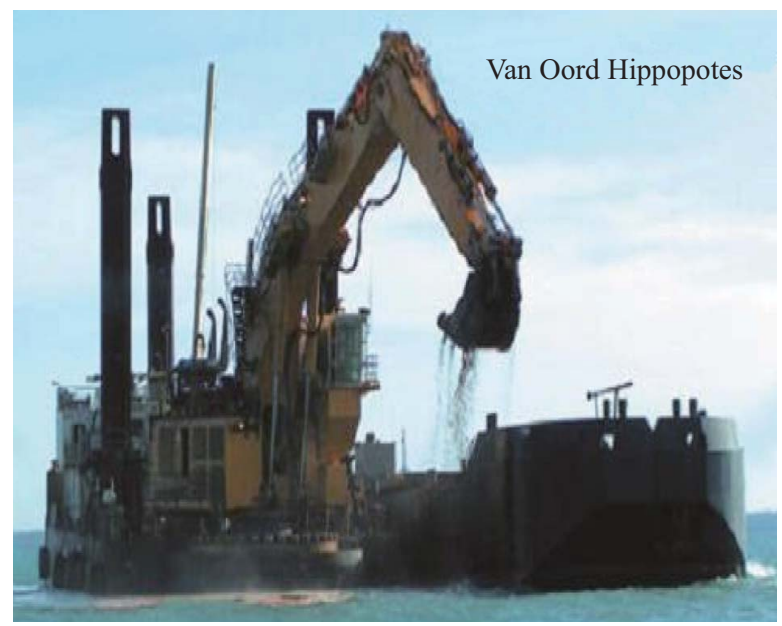

Fig. 6. Schematic showing the dredger for BD.

b. When the water depth is below $10 \mathrm{~m}$, the Cutter Suction Dredger (CSD) is selected as shown in Fig. 5. The dredged depth of each layer is about $0.5-1.5 \mathrm{~m}$ and depends on equipment and efficiency, and the large-sized machines can reach dredging depth greater than $30 \mathrm{~m}$ for each layer depth. Other opinion such as the Backhoe Dredger (BD), as shown in Fig. 6, can also be selected for the dredged depth of each layer is about 1.5-3 m and depends on equipment and efficiency, and the large-sized machines can reach dredging depth greater than $15 \mathrm{~m}$ for each layer depth. The dredger type for this study is suggested in Table 3.

\section{2) Analysis Results}

A. Water depth $>10 \mathrm{~m}$ : The main soil layer belongs to sandy sand, so that THSD can fit the SPT-N value lower than twenty in sandy soil and also fit the SPT-N value lower than thirty in mixed gravel-sand soil. Results in previous section show that mostly SPT-N values of drilling positions are smaller 
Table 4. Wave condition and estimation of erosion depth at each coastal region.

\begin{tabular}{|c|c|c|c|c|c|c|c|}
\hline & $\begin{array}{c}T \\
(\mathrm{~s})\end{array}$ & $\begin{array}{c}L \\
(\mathrm{~m})\end{array}$ & $\begin{array}{c}d \\
(\mathrm{~m})\end{array}$ & $\begin{array}{c}H \\
(\mathrm{~m})\end{array}$ & $\begin{array}{c}D \\
(\mathrm{~m})\end{array}$ & $U_{R P}$ & $\begin{array}{c}S \\
(\mathrm{~m})\end{array}$ \\
\hline $\begin{array}{c}\text { Taichung } \\
\text { Harbor }\end{array}$ & 11.3 & 165.0 & 31 & 7.3 & 0.914 & 425.16 & 0.46 \\
\hline Kwun-Tong & 12.9 & 216.8 & 41.5 & 9.4 & 0.914 & 653.32 & 0.55 \\
\hline Hsinchu & 12.7 & 152.4 & 17 & 9.1 & 0.914 & 4258.5 & 1.18 \\
\hline
\end{tabular}

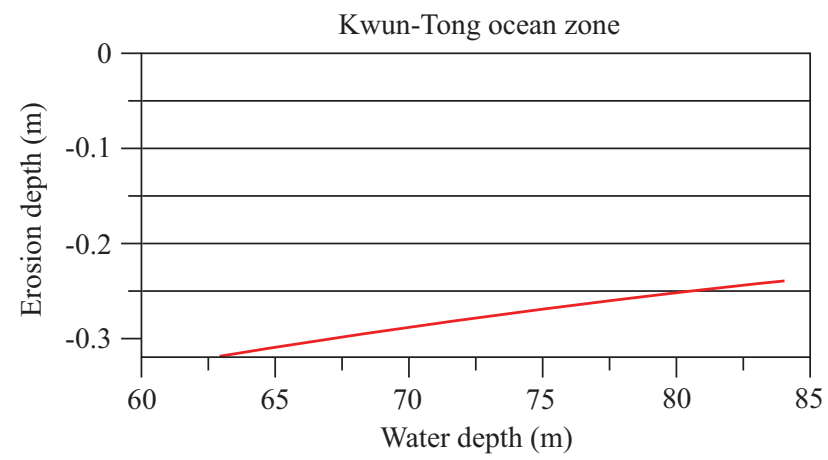

Fig. 7. Relationship between erosion depth and water depth for KwunTong area.

than four. It belongs to extreme loose and soft layer, and hence the adaptability of dredger is better.

B. Water depth < $10 \mathrm{~m}$ : Based on collected sono-probe results presently, except for the sandy seabed at the coastal region in Taoyuan, the algae-reef as hard as rock still distributes around the pipeline area. But the coastal region in Taichung still belongs to sandy seabed mainly. Thus it can be known that BD can fit the geology more in Taoyuan, but on the contrary both CSD and BD can fit the geology in Taichung Harbor.

\section{Assessment of Erosion Potential}

\section{1) Analysis Method}

Viewed in seabed erosion aspect around the undersea pipeline, because the pipeline is laid in the seabed, its existence causes up-lift force effect near the flow field, and induces erosion and scour on the seabed surface. The variability of flow field induces eddy current nearby pipeline to cause these phenomenons.

In this study, the better analysis method is to determine erosion directly. Based on the proposed result by Cevik and Yüksel (1999) [3], the relative erosion depth $(S / D)$ nearby undersea pipeline corresponds to modified parameter, $U_{R P}$, the relevant equations are as follows,

$$
\begin{aligned}
U_{R P} & =H^{3} L^{2} / d^{3} D^{2} \\
\frac{S}{D} & =0.042 U_{R P}^{0.41}
\end{aligned}
$$

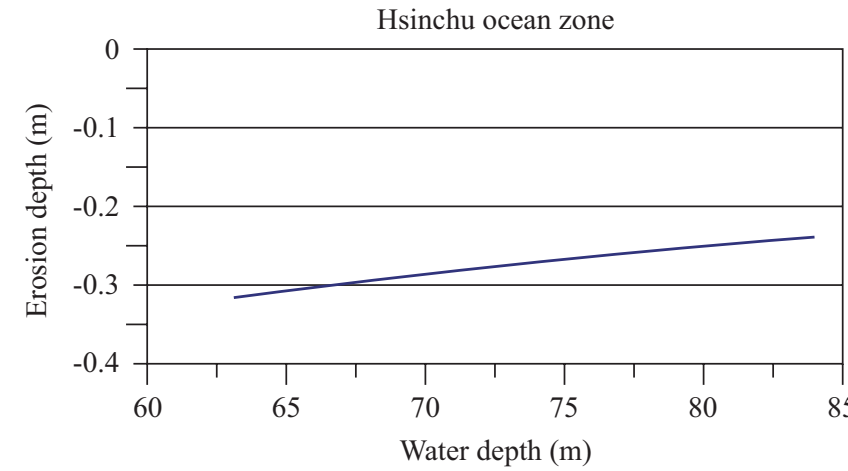

Fig. 8. Relationship between erosion depth and water depth for Hsinchu area.

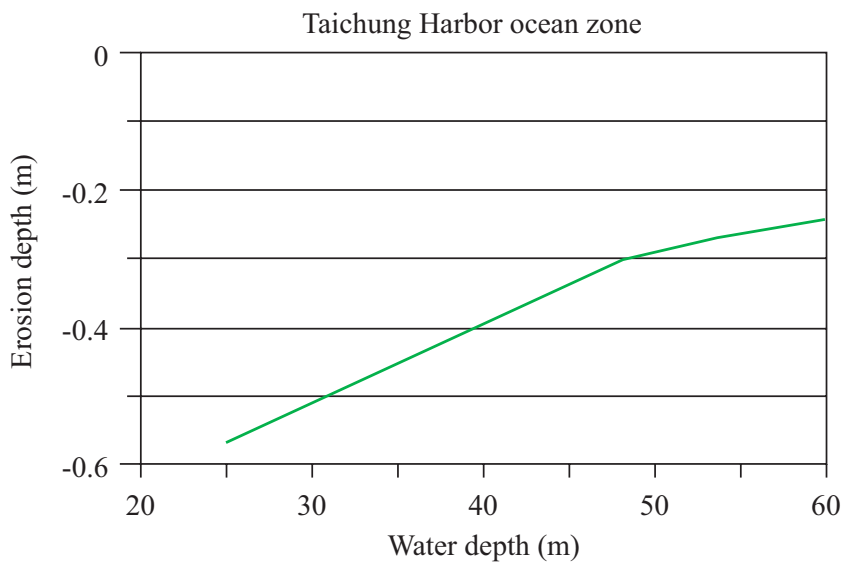

Fig. 9. Relationship between erosion depth and water depth for Taichung Harbor area.

where $S$ is erosion depth, $D$ is outside radius of undersea pipeline, $H$ is wave height, $L$ is wave length, and $d$ is water depth.

In order to understand the influence and behavior of undersea pipeline during typhoon action, three different typhoon waves with 50 years of return period were evaluated, including Taichung Harbor, Kwun-Tong and Hsinchu. The wave condition and the estimation of erosion depth at each region are shown in Table 4. The source data for wave condition are obtained from $\left[120.39^{\circ} \mathrm{E}, 24.3^{\circ} \mathrm{N}\right],\left[121.03^{\circ} \mathrm{E}, 25.10^{\circ} \mathrm{N}\right]$ and $\left[120.87^{\circ} \mathrm{E}, 24.86^{\circ} \mathrm{N}\right]$ respectively, and the major typhoon wave direction is North-NorthEast in the return period. And the maximum erosion depth is about $1.2 \mathrm{~m}$ in Hsinchu, the other place is about $0.4 \mathrm{~m}$ to $0.6 \mathrm{~m}$.

\section{2) Analysis Results}

Based on the analysis method with erosion seabed in previous section, the erosion depth above the water depth of $25 \mathrm{~m}$ can be estimated using (4) and (5) from the typhoon wave data in Taichung Harbor during 1940-2006.

The plots of the erosion depth versus the water depth from typhoon wave data are illustrated in Figs. 7 to 9, respectively. 


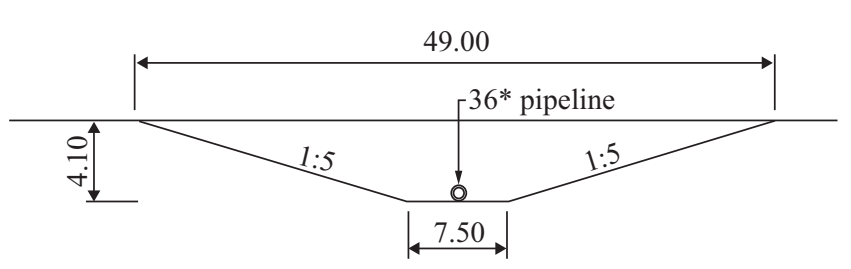

(a) the excavated design section below $25 \mathrm{~m}$ of water depth

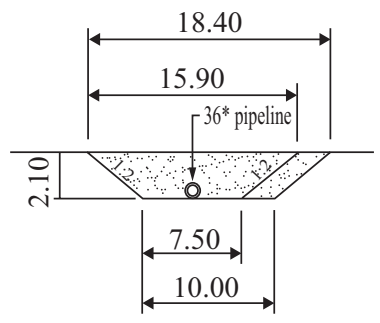

(b) the excavated design section above $25 \mathrm{~m}$ of water depth

Fig. 10. The design profile for excavated pipeline of seabed.

\section{Assessment of Pipeline Stability}

\section{1) Analysis Method}

The pipeline stability includes two parts mainly in this section. First, using the numerical program, STABL, the general solution of slope stability problems by two-dimensional limiting equilibrium methods was evaluated $[1,2,7]$. It allows the analysis of reinforced soil slopes with geosynthetics, nailing, and tiebacks using the Bishop, Spencer and Janbu methods. STABL features unique random techniques for generation of potential failure surfaces for subsequent determination of the more critical surfaces and their corresponding factors of safety. One technique generates circular; another, surfaces of sliding block character; and a third, more general irregular surfaces of random shape. Specific trial failure surface can also be specified by the user.

Second, the main object is to evaluate the liquefaction potential of seabed soil after buried undersea pipeline. In general, it must be considered two factors, including water depth of buried pipeline and main outer force action. Hence this study is adopted earthquake force and wave force separately to assess both earthquake and typhoon wave loading induced the liquefaction potential. Detailed procedures are presented in the following paragraphs.

A. The excavation of slope stability analysis

The design profile for excavated trench before buried the undersea gas pipeline are illustrated in Fig. 10. STABL program is used to analyze slope stability for excavated section in Fig. 10 and the analysis does not consider the factor of seepage and pore water pressure in this study.

Nine positions were adopted to analyze at pipeline path from Fig. 2, and the choice of hole position is corresponding to triaxial cyclic test. The north region selects No. 1, 4, 9, the center region selects No. 13, 19, 24, and the south region selects No. 28, 30, and 32. These positions are all above $25 \mathrm{~m}$ of water depth.

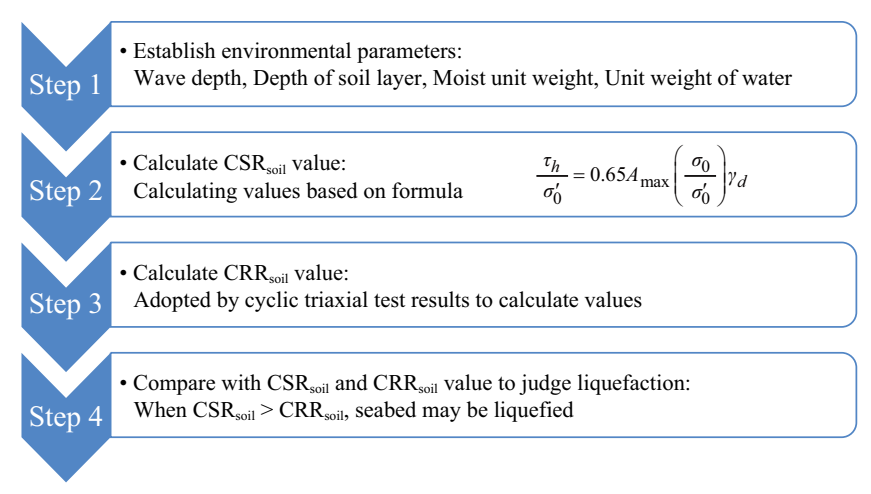

Fig. 11. Flow chart assessing earthquake loading induced liquefaction.

B. Liquefaction assessment after buried undersea pipeline

Seed and Idriss [14] developed the simplified assessment for soil liquefaction, this approach is based on the CSR and cyclic resistance ratio (CRR) induced by earthquake loading to evaluate for liquefaction potential. In addition, Ishihara and Yamazaki [10] proposed an approach to evaluate the seabed soil liquefaction. This approach is based on the CSR induced by wave loading. In this section, both two approaches are adopted to evaluate liquefaction after buried undersea pipeline.

(a) Earthquake loading induced liquefaction

According to Seed and Idriss [14], Seed [13], Youd et al. [19], and Idriss and Boulanger [9], the earthquake-induced maximum ground surface acceleration $\left(A_{\max }\right)$ may be used to estimate the CSR through Step 2 in Fig. 11, but it does not consider the magnitude scaling factor. When CSR > CRR, it is possible to liquefy. In this study, CRR is obtained from results of cyclic triaxial test in previous section to assess and analyze soil liquefaction.

The CRR is the in situ cyclic undrained shear strength of the soil mobilized for the equivalent number of stress cycles developed due to the earthquake and CSR is the average shear stress level developed in the ground duo to earthquake loading at the depth under consideration. According to the simplified method, the flow chart of assessing earthquake induced liquefaction is shown in Fig. 11.

(b) Typhoon wave loading induced liquefaction

Ishihara and Yamazaki [10] developed an approach called the seabed liquefaction-potential assessment approach based on small-amplitude wave theory. When the wave acts on the seabed, the pore water pressure can be generated from the cyclic loading induced by wave. The cyclic shear stress ratio is obtain from wave induced shear stress and mean effective confining pressure.

However, the approach has limitations. First, An adopted value of $N c=100$ is used for $N_{e q}$, which leads to inaccuracies in calculating CSR for triaxial testing. Second, this approach does not account for the fact that different relative density begin to exhibit number of cycle behavior at different strain level. Chien et al. [6] proposed that if wave loading is the main acting force to the seabed, " $N_{e q}$ " should be equal to $N c=$ 


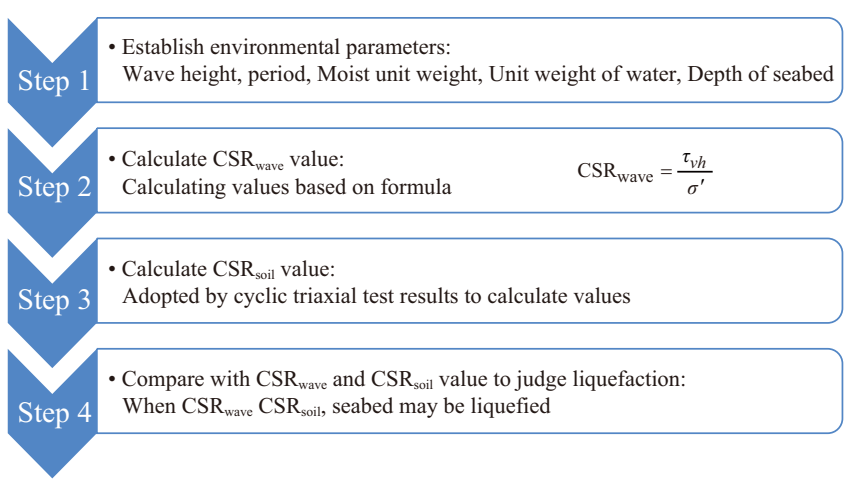

Fig. 12. Flow chart assessing wave loading induced liquefaction.

1000. In addition, this method is also considered seabed soil characteristic and wave condition in-situ. In this study, this method is an integrated and more general approach than the conventional method for wave induced seabed liquefaction problem. Hence, the method established by this study makes it possible to accurately evaluate liquefaction under wave loading.

Sumer and Fredsøe [16] proposed a simplified analytical solution which the condition of the horizontal seabed is assumed to be unlimited thickness. This popular analytical solution of the stresses is for isotropic, poro-elastic media of seabed under the assumptions of fully saturation, and linear wave's action is developed by Yamamoto et al. [18]. And Chang [5] also indicated that the results of hydraulic model test are smaller than the results of analytical solution for assessment model by Yamamoto et al. [18] and Hsu and Jeng [8] Therefore, this study adopted the analytical solution of Yamamoto et al. [18] to assess the internal dynamic stresses induced by wave loading in the field, although this method is comparatively simple, but the influence on every stress of each parameter is easier to observe in the formula.

The dynamic stress of surface seabed is influenced by the wave height and period mainly. Period, T, and water depth, $\mathrm{h}$, are taken into the dispersion relation equation to calculate the wave length, $\mathrm{L}$. In order to estimate the dynamic stress of surface seabed induces by wave, this research use the undrained shear strength data from cyclic triaxial test.

In accordance with the demand of testing results, the theoretical solution of Yamamoto et al. [18] can be obtained the vertical shear stress and the mean effective stress at any depth below the seabed surface, as shown in Step 2 of Fig. 12.

The stability or liquefaction under wave loading can be evaluated by comparing wave induced cyclic shear stress ratio with liquefaction resistance strength as identified in Fig. 3 from test results. The flow chart of assessing wave loading induced liquefaction is shown in Fig. 12.

\section{2) Analysis Results}

A. Results of slope stability

Using circular slide of Janbu method in STABL program to analyse slope stability, it can be obtained safety factor in each
Table 5. Parameters and results of slope stability analysis.

\begin{tabular}{|c|c|c|c|c|c|c|}
\hline No. & $\begin{array}{c}z \\
(\mathrm{~m})\end{array}$ & $\begin{array}{c}h \\
(\mathrm{~m})\end{array}$ & $\begin{array}{c}\gamma_{\text {sat }} \\
\left(\mathrm{kN} / \mathrm{m}^{3}\right)\end{array}$ & $\begin{array}{c}c \\
(\mathrm{kPa})\end{array}$ & $\begin{array}{c}\phi \\
(\text { degree })\end{array}$ & $\begin{array}{c}\text { FS } \\
(\mathrm{Janbu})\end{array}$ \\
\hline 32 & $1-1.2$ & 25 & 19.37 & 0.284 & 30.54 & 1.57 \\
\hline 30 & $1-1.2$ & 51 & 19.73 & 0.294 & 24.66 & 1.21 \\
\hline 28 & $1-1.2$ & 54 & 20.76 & 0.438 & 37.31 & 2.18 \\
\hline 24 & $1.8-2$ & 54 & 20.42 & 0.383 & 30.55 & 1.57 \\
\hline 19 & $1-1.2$ & 57 & 20.23 & 0.371 & 32.76 & 1.84 \\
\hline 13 & $0.9-1.5$ & 69 & 19.37 & 0.395 & 25.45 & 1.34 \\
\hline 9 & $2.1-2.4$ & 81 & 19.98 & 0.145 & 20.35 & 0.91 \\
\hline 4 & $2.1-2.4$ & 72 & 20.27 & 0.464 & 27.61 & 1.47 \\
\hline 1 & $1.8-2$ & 38 & 20.19 & 0.456 & 34.76 & 1.94 \\
\hline
\end{tabular}

excavation profile and listed in Table 5.

$\phi$ and $c$ of the seabed soil have a great impact for slope stability analysis. It can be found that when the difference of soil cohesion is limited as shown in Table 5 , the variation of $\phi$ has a larger influence on safety factors, indicating a greater impact on $\phi$ than soil cohesion. In addition, soil samples have a lot of content with silt or shell sand because in-situ samples sent to the laboratory was subjected to disturbance and water content dissipation. It may raise unexpected errors of saturated unit weight and water content and may affect the variation of strength parameters of remolded specimens.

The variation of water depth in this research area ranges below from $25 \mathrm{~m}$ to $81 \mathrm{~m}$. From viewpoint of undersea slope stability, as a result of slope failure may be occurred at very gradual slope, hence the chosen drilling hole in previous section belong to toe-circle failure. However, the excavation depth is only $2.1 \mathrm{~m}$, it is possible to cause shallow layer sliding or floating, and to make soil strength diminish to failure. This behavior may be a reason among usually inducing undersea pipeline destruction. Based on the design profile for excavated trench of Fig. 10, this study chooses a cross-section between $450 \mathrm{~m}$ and $550 \mathrm{~m}$, and adopts different gradient and water depth to simulate slope stability of seabed.

Based on different water depth in each drilling hole, the relevant parameters from physical test and sea level are given in program to perform slope stability analysis. The results of slope stability analysis are shown in Table 5 . The safety factor of No. 9 is lower than 1. It can be illustrated the higher slide possibility in this position than others, as shown in Fig. 13.

It is well known that the strength parameter of the soil plays an important role for the slope stability. Since the soil property in No. 9 is classified as the silt with a very low strength parameter, it should pay attention to the stability and safety measures during construction. The safety factor of No. 28 is the highest and more safety than other position as shown in Fig. 14.

B. Results of pipeline stability

(a) Earthquake loading causing liquefaction

Results show that the CRRs induced by seabed soil in center and south region of pipeline are lower than CSRs induced 


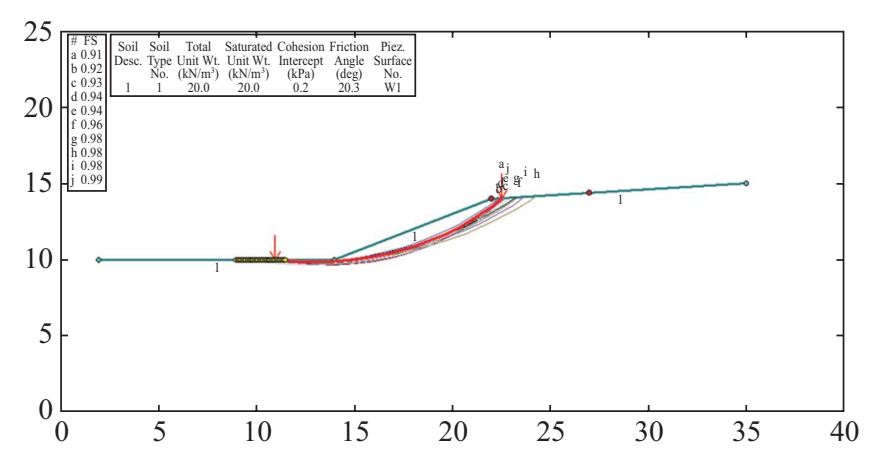

Fig. 13. Safety factor (0.91) of No. 9 and its slide circle.

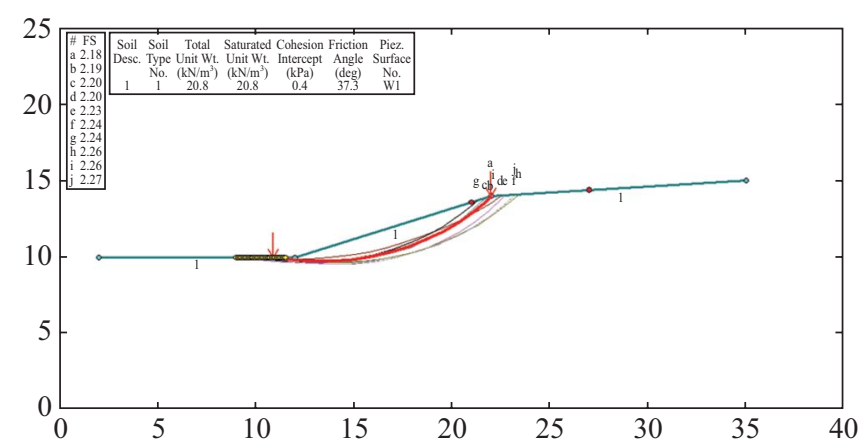

Fig. 14. Safety factor (2.18) of No. 28 and its slide circle.

Table 6. Results of earthquake causing liquefaction.

\begin{tabular}{|r|c|c|r|c|c|c|c|c|}
\hline No. & $\begin{array}{c}z \\
(\mathrm{~m})\end{array}$ & $\begin{array}{c}\rho \\
\left(\mathrm{g} / \mathrm{cm}^{3}\right)\end{array}$ & $\begin{array}{c}\sigma^{\prime} \\
(\mathrm{kPa})\end{array}$ & $\begin{array}{c}\sigma_{\text {total }} \\
(\mathrm{kPa})\end{array}$ & $\begin{array}{c}A_{\max } \\
(\mathrm{g})\end{array}$ & CSR & $\mathrm{CRR}$ & $\begin{array}{c}\bullet \text { liquefied } \\
\text { onon-liquefied }\end{array}$ \\
\hline 1 & 1 & 20.59 & 10.49 & 20.59 & 0.23 & 0.29 & 0.45 & $\circ$ \\
\hline 3 & 1 & 20.75 & 10.65 & 20.75 & 0.23 & 0.29 & 0.33 & $\circ$ \\
\hline 10 & 1 & 19.93 & 9.83 & 19.93 & 0.33 & 0.43 & 0.33 & $\bullet$ \\
\hline 13 & 1 & 20.38 & 10.28 & 20.38 & 0.33 & 0.42 & 0.20 & $\bullet$ \\
\hline 19 & 2 & 20.74 & 21.27 & 41.48 & 0.33 & 0.41 & 0.17 & $\bullet$ \\
\hline 23 & 2 & 20.06 & 19.89 & 40.12 & 0.33 & 0.42 & 0.33 & $\bullet$ \\
\hline 28 & 2 & 19.90 & 19.59 & 39.80 & 0.33 & 0.42 & 0.44 & $\circ$ \\
\hline 30 & 1 & 19.49 & 9.39 & 19.49 & 0.33 & 0.44 & 0.23 & $\bullet$ \\
\hline \multirow{2}{*}{32} & 1 & 21.06 & 10.96 & 21.06 & 0.33 & 0.41 & 0.26 & $\bullet$ \\
\cline { 2 - 8 } & 2 & 21.06 & 21.91 & 42.12 & 0.33 & 0.4 & 0.36 & $\bullet$ \\
\hline
\end{tabular}

by earthquake loading. It is possible to occur liquefaction of seabed. On the other hand, CRRs of No. 1 and No. 3 in north region and No. 28 in south region of pipeline are all higher than CSRs, Hence these position does not occur liquefaction phenomenon. The analysis results are shown in Table 6 .

If considering the analysis area under sea surface, the maximum acceleration, $A_{\max }$, can be reduced by half base upon deterministic seismic hazard analysis (DSHA). The analysis results are shown in Table 7 . The liquefaction only occurs in center region of pipeline, not in other regions of pipeline.

(b) Typhoon wave loading causing liquefaction

Results show that the CSRs induced by seabed soil at the
Table 7. Results of earthquake causing liquefaction $\left(A_{\max }\right.$ reduced by half).

\begin{tabular}{|r|c|c|r|c|c|c|c|c|}
\hline No. & $\begin{array}{c}z \\
(\mathrm{~m})\end{array}$ & $\begin{array}{c}\rho \\
\left(\mathrm{g} / \mathrm{cm}^{3}\right)\end{array}$ & $\begin{array}{c}\sigma^{\prime} \\
(\mathrm{kPa})\end{array}$ & $\begin{array}{c}\sigma_{\text {total }} \\
(\mathrm{kPa})\end{array}$ & $\begin{array}{c}A_{\max } \\
(\mathrm{g})\end{array}$ & $\mathrm{CSR}$ & $\mathrm{CRR}$ & $\begin{array}{l}\bullet \text { liquefied } \\
\text { onon-liquefied }\end{array}$ \\
\hline 1 & 1 & 20.59 & 10.49 & 20.59 & 0.12 & 0.15 & 0.45 & $\circ$ \\
\hline 3 & 1 & 20.75 & 10.65 & 20.75 & 0.12 & 0.15 & 0.33 & $\circ$ \\
\hline 10 & 1 & 19.93 & 9.83 & 19.93 & 0.17 & 0.21 & 0.33 & $\circ$ \\
\hline 13 & 1 & 20.38 & 10.28 & 20.38 & 0.17 & 0.21 & 0.20 & $\bullet$ \\
\hline 19 & 2 & 20.74 & 21.27 & 41.48 & 0.17 & 0.20 & 0.17 & $\bullet$ \\
\hline 23 & 2 & 20.06 & 19.89 & 40.12 & 0.17 & 0.21 & 0.33 & $\circ$ \\
\hline 28 & 2 & 19.90 & 19.59 & 39.80 & 0.17 & 0.21 & 0.44 & $\circ$ \\
\hline 30 & 1 & 19.49 & 9.39 & 19.49 & 0.17 & 0.22 & 0.23 & $\circ$ \\
\hline \multirow{2}{*}{32} & 1 & 21.06 & 10.96 & 21.06 & 0.17 & 0.20 & 0.26 & $\circ$ \\
\cline { 2 - 8 } & 2 & 21.06 & 21.91 & 42.12 & 0.17 & 0.20 & 0.36 & $\circ$ \\
\hline
\end{tabular}

Table 8. Results of wave action causing liquefaction.

\begin{tabular}{|r|c|c|c|c|c|c|c|}
\hline No. & $\begin{array}{c}h \\
(\mathrm{~m})\end{array}$ & $\begin{array}{c}L \\
(\mathrm{~m})\end{array}$ & $\begin{array}{c}P_{0} \\
(\mathrm{kPa})\end{array}$ & $\begin{array}{c}\text { Shear } \\
\text { Stress } \\
(\mathrm{kPa})\end{array}$ & CSR & CRR & $\begin{array}{l}\bullet \text { liquefied } \\
\text { onon-liquefied }\end{array}$ \\
\hline 1 & 38 & 210.9 & 27.74 & 0.80 & 0.08 & 0.39 & $\circ$ \\
\hline 3 & 71 & 246.3 & 15.12 & 0.38 & 0.04 & 0.28 & $\circ$ \\
\hline 10 & 77 & 249.3 & 13.37 & 0.33 & 0.03 & 0.24 & $\circ$ \\
\hline 13 & 69 & 238.8 & 14.58 & 0.37 & 0.04 & 0.09 & $\circ$ \\
\hline 19 & 57 & 230.3 & 18.59 & 0.96 & 0.05 & 0.10 & $\circ$ \\
\hline 23 & 57 & 230.3 & 18.59 & 0.96 & 0.05 & 0.20 & $\circ$ \\
\hline 28 & 54 & 188.7 & 11.89 & 0.74 & 0.04 & 0.26 & $\circ$ \\
\hline 30 & 51 & 186.9 & 12.86 & 0.42 & 0.04 & 0.11 & $\circ$ \\
\hline 32 & 25 & 153.7 & 23.50 & 0.92 & 0.08 & 0.19 & $\circ$ \\
\cline { 5 - 8 } & & & 1.77 & 0.08 & 0.16 & $\circ$ \\
\hline
\end{tabular}

whole undersea pipeline are higher than CSRs induced by wave action, so it can not easier occur liquefaction phenomenon. The results are shown in Table 8.

\section{CONCLUSIONS}

In this study, a method is proposed to assess the wave and earthquake induced liquefaction potential for undersea gas pipeline using the strength parameters from the cyclic triaxial test and the direct shear test in the laboratory.

Based on the analysis results, SPT-N value are all lower than thirty for study area at water depth large than $10 \mathrm{~m}$. The adaptability of TSHD can be fitted dredging request. For study area at water depth below $10 \mathrm{~m}$, because CSD and BD can be suitable for any soil properties, it also can be fitted dredging request. Because the SPT-N value is obtained from general empirical equation, it may have some difference with in-situ results ,but the dredgers can be adopted in general condition.

According to 50 years return period of typhoon wave condition along the undersea gas pipeline, results show that the maximum erosion depth is about $1.18 \mathrm{~m}$ at Hsinchu coastal area. The erosion depth both at Kwun-Tong and Taichung 
Harbor coastal area are about $0.46 \mathrm{~m}$ and $0.55 \mathrm{~m}$ respectively.

The safety factor of No. 9 at Hsinchu coastal area is lower than 1 , it can be illustrated the higher slide possibility in this position, and soil property in No. 9 belong to silt. It should pay attention to stability and safety measures during construction. The safety factor of No. 28 near by Taichung Harbor reaches 2.18 , and the safety factor of No. 1 near by Taoyuan reaches 1.94 . It can be shown that undersea gas pipeline is difficult to cause failure.

Under cyclic earthquake loading, CRR larger than 0.44 is difficult to cause liquefaction failure. But under typhoon wave loading, CSR at each drilling hole induced by wave forces are all lower than 0.1 except for No. 32. Because the water depth is between $38 \mathrm{~m}$ and $80 \mathrm{~m}$, it may not induce liquefaction. All three section of pipeline don't occur liquefaction under wave action, but it is possible to occur liquefaction under earthquake loading except for No. 1, 3 and 28. It should pay attention to soil improvement and safety measures of pipeline stability.

If considering the analysis area under sea surface, the maximum acceleration, $A_{\max }$, can be reduced by half base upon DSHA.

Results show that CRR is greater than 0.23 and it may not able to occur liquefaction. But the liquefaction risk is high in center region of undersea pipeline due to the low CRR value. In addition, results obtained show that other regions have no liquefaction phenomenon. Since the predicted buried path of undersea gas pipeline may encounter existing fault conformation, it must pay attention to near-fault effect.

As a result, this method provides an accurate analysis technique for evaluating wave induced seabed liquefaction. This proposed approach may be easily applied to practical marine engineering problems involving soil-pipeline interaction such as wave action and earthquake loading analysis.

Finally, although the present method is only investigated into pipeline stability by wave inducing soil liquefaction, it provide a reasonable assessment for deep undersea pipeline. Using a similar approach, the interaction between wave, undersea gas pipeline and soil liquefaction can be studied in the future.

\section{ACKNOWLEDGMENTS}

This research was supported by Real World Engineering Consultants INC., Taiwan and referred references by CECI Engineering Consultant Inc., Taiwan, and project by NSC 972221-E-019-030. Grateful appreciation is expressed to their support.

\section{NOTATION}

The following symbols are used in this research:

$c=\quad$ soil cohesion

$\phi=\quad$ soil friction angle

$\sigma_{d}=$ the deviator stress

$\sigma_{3}=$ the effective confining pressure

$\begin{array}{ll}N c= & \text { number of stress cycle } \\ M= & \text { earthquake magnitude } \\ N_{e q}= & \text { number of equivalent cycle } \\ \text { CSR }= & \text { cyclic shear stress ratio } \\ \text { CRR }= & \text { cyclic resistance ratio } \\ N= & \text { number of standard penetration } \\ U_{R P}= & \text { the pipe Ursell number } \\ H= & \text { wave height } \\ L= & \text { wave length } \\ d= & \text { water depth } \\ D= & \text { outside radius of undersea pipeline } \\ S= & \text { erosion depth } \\ A_{\text {max }}= & \text { the peak horizontal acceleration } \\ \tau_{h}= & \text { the horizontal shear stress } \\ \sigma_{0}= & \text { the initial stress } \\ \sigma^{\prime}= & \text { the effective stress } \\ \gamma_{d}= & \text { the stress reduction coefficient } \\ z= & \text { the depth below ground surface } \\ \text { FS }= & \text { slope safety factor } \\ \gamma_{\text {sat }}= & \text { saturated unit weight } \\ \rho= & \text { seabed soil unit density } \\ \sigma_{\text {total }}= & \text { the total stress } \\ P_{0}= & \text { the surface wave pressure } \\ & \end{array}$

\section{REFERENCES}

1. Bishop, A. W., "The use of the slip circle in the stability analysis of slopes," Geotechnique, Vol. 5, No. 1, pp. 7-17 (1955).

2. Bromhead, E. N., The Stability of Slopes, 2nd Ed., Blackie Academic and Professional, London (1992).

3. Cevik, E. and Yüksel, Y., "Scour under submarine pipelines in waves in shoaling conditions," Journal of Waterway, Port, Coastal, and Ocean Engineering, Vol. 125, No. 1, pp. 9-19 (1999).

4. Chang, C.-H., Chien, L.-K., and Chang, Y.-H., "3-D liquefaction potential analysis of seabed at nearshore area," Journal of Marine Science and Technology, Vol. 12, No. 3, pp. 141-151 (2004).

5. Chang, S. C., Chien, L. K., Lin, J. G., and Chiu, Y. F., "An experimental study on progressive wave-induced dynamic stresses in porous seabed soil," Journal of Marine Science and Technology, Vol. 15, No. 2, pp. 129140 (2007)

6. Chien, L.-K., Chang, C.-H., and Chang, Y.-H., "Liquefaction resistance in seabed sand under different loading periods," Geotechnical Engineering Journal, Vol. 36, No. 1, pp. 13-23 (2005).

7. Duncan, J. M., "Limit equilibrium and finite-element analysis of slopes," Journal of Geotechnical Engineering, Vol. 122, No. 7, pp. 577-596 (1995).

8. Hsu, J. R. C. and Jeng, D. S., "Wave-induced soil response in an unsaturated anisotropic seabed of finite thickness," International Journal for Numerical and Analytical Methods in Geomechanics, Vol. 18, No. 11, pp. $785-807$ (1994).

9. Idriss, I. M. and Boulanger, R. W., "Semi-empirical procedures for evaluating liquefaction potential during earthquakes," Soil Dynamics and Earthquake engineering, Vol. 26, pp. 115-130 (2006).

10. Ishihara, K. and Yamazaki, A., "Analysis of wave-induced liquefaction in sea-bed deposits of sand," Soils and Foundations, Vol. 24, No. 3, pp. 85-100 (1984).

11. Kung, G. T. C., Lee, D. H., and Tsai, P. H., "Performance of DMT-based liquefaction evaluation methods on case histories of Chi-Chi earthquake," Journal of Marine Science and Technology, Vol. 17, No. 4, pp. 283-292 (2009).

12. Meyergof, G. G., "Penetration test and bearing capacity of cohesionless soils," Journal of the Soil Mechanics and Foundation Division, ASCE, 
Vol. 82, No. 1, pp. 1-19 (1956).

13. Seed, H. B., "Soil liquefaction and cyclic mobility evaluation for level ground during earthquakes," Journal of the Geotechnical Engineering Division, ASCE, Vol. 105, No. GT2, pp. 201-255 (1979).

14. Seed, H. B. and Idriss, I. M., "Simplified procedure for evaluating soil liquefaction potential," Journal of the Soil Mechanics and Foundation Division, ASCE, Vol. 97, No. SM9, pp. 1249-1273 (1971).

15. Seed, H. B., Martin, P. P., and Lysmer, J., "Pore-water pressure changes during soil liquefaction," Journal of the Geotechnical Engineering Division, ASCE, Vol. 102, No. 4, pp. 323-346 (1976).

16. Sumer, B. M. and Fredsøe, J., The Mechanics of Scour in the Marine Environment, World Scientific Publishing Co. Inc., N. Y. (2002).

17. Terzaghi, K., Peck, R. B., Ralph, B., and Mesri, G., Soil Mechanics in
Engineering Practice, 3rd Edition, John Wiley \& Sons, N. Y. (1996).

18. Yamamoto, T., Koning, H. L., Sellmeijer, H., and Hijum, E. V., "On the response of a poro-elastic bed to water waves," Journal of Fluid Mechanics, Vol. 87, pp. 193-206 (1978).

19. Youd, T. L., Idriss, I. M., Andrus, R. D., Arango, I., Castro, G., Christian, J. T., Dobry, R., Finn, W. D. L., Harder, L. F., Hynes, M. E., Ishihara, K., Koester, J. P., Liao, S. C., Marcuson, III W. F., Martin, G. R., Mitchell, J. K., Moriwaki, Y., Power, M. S., Robertson, P. K., Seed, R. B., and Stokoe, II K. H., "Liquefaction resistance of soils: Summary report from 1996 NCEER and 1998 NCEER/NSF workshops on evaluation of liquefaction resistance of soils," Journal of Geotechnical and Geoenvironmental Engineering, ASCE, Vol. 127, No. 10, pp. 817-833 (2001). 